\title{
Viewing the Future of Nuclear Power Plants Following the 2011 Disaster in Fukushima Nuclear Power Plant
}

\author{
Shervin Goudarzi ${ }^{*}$, Fatemeh Dadgarnejad ${ }^{2}$, Hojat Babaee ${ }^{1}$ \\ ${ }^{1}$ Plasma and Nuclear Fusion Research School, Nuclear Science and Technology Research Institute, Atomic \\ Energy Organization of Iran, Tehran, Iran \\ ${ }^{2}$ Nuclear Science and Technology Research Institute, Atomic Energy Organization of Iran, Tehran, Iran \\ Email: sgoudarzi@aeoi.org.ir
}

Received 4 May 2015; accepted 16 May 2015; published 19 May 2015

Copyright (C) 2015 by authors and Scientific Research Publishing Inc.

This work is licensed under the Creative Commons Attribution International License (CC BY). http://creativecommons.org/licenses/by/4.0/

(c) (i) Open Access

\begin{abstract}
Concerning the increasing global energy demand, the current paper considers nuclear energy as a solution. Within this context, the $\mathbf{2 0 1 1}$ disaster in Fukushima Nuclear Power Plant and, particularly, the technical disorders in boiling water reactors are explained. The deficiency of safety technique in boiling water reactors is explained. The deficiencies in safety procedure of this type of reactors manifested during 2011 earthquake and subsequent tsunami are explained. To complete the discussion, the newer technologies of reactors enabling them to act more safely during natural disasters are introduced. These investigations indicate that despite improvement in the fission reactor technologies, the danger embedded in them still remains. Therefore, the nuclear fusion using Deuterium-Tritium reaction is the best way forward for energy production in the future, and the best candidate of this type of reactors is Tokamak.
\end{abstract}

\section{Keywords}

Nuclear Fission, Nuclear Fusion, Fukushima, Tsunami, Waste, Boiling Water Reactors

\section{Introduction}

Considering the increasing world and urban population and the entry of less developed and developing countries into energy demand market, global energy consumption increases dramatically. Meanwhile the energy demand of two economic giant countries such as China and India has considerable share in that global increase. The In-

${ }^{*}$ Corresponding author.

How to cite this paper: Goudarzi, S., Dadgarnejad, F. and Babaee, H. (2015) Viewing the Future of Nuclear Power Plants Following the 2011 Disaster in Fukushima Nuclear Power Plant. Open Journal of Applied Sciences, 5, $220-225$. 
ternational Institute of Applied Systems and International Energy Council estimates that, depending on how to control energy consumption, the global energy in year 2100 would be two to four times the current energy demand [1] [2]. Currently, fossil fuels (coal, oil and gas) meet $80 \%$ of world energy demand. However, these types of energy sources are limited and using of them has caused enormous environmental problems (greenhouse gases, acid rain, increasing the temperature of the world, etc.).

Concerning the renewable energies, such as wind, solar, geothermal and tide, it is remote possibility that these types of energy can meet a major portion of energy demand in the next few decades [1] [3].

The energy produced from nuclear fission is clean, does not produce any form of green house gases and does not increase the global temperature. However, the public concerns regarding the overall safety of nuclear power plants and the accidents in these plants of which the most famous ones are Three Mile Island Nuclear power plant in USA (March 1979) and Chernobyl nuclear power plant in Soviet Union (April 1986), have slowed down using of fission energy. Recently, the accident in Fukushima nuclear power plants has brought the issue of safety of the nuclear energy into attention once more. In general, safety is the most important issue in everything connected with nuclear technology and in case of nuclear power plants relates to three points/issues [1] [3]: 1) losing control and subsequent explosion in a nuclear power plant, 2) the existence of radioactive wastes and 3) destruction of a nuclear power plant as a result of non-technical cause such as war or natural disaster.

Concerns over the possibility of producing materials for military purpose are another problem which has led the expansion of nuclear power plants to become a political issue.

\section{Fukushima Disaster}

A massive earthquake of magnitude of 8.9 in Richter scale hit on Friday $11^{\text {th }}$ March 2011 at 2.46 p.m. in Japan and subsequent massive tsunami caused tremendous damage to the east coast of Japan. Three units of Boiling Water Reactors (BWR) in Fukushima Daiichi nuclear cite were distracted in this accident due to the lack of heat transfer from core to outside.

All nuclear plants are equipped with earthquake recognition system and chain reaction shut down or emergency shut down system in case of an earthquake. This is done using control rods to stop the chain reaction and switch off the reactor. Eleven reactors at four nuclear power plants in the region were operating at the time and all shut down automatically when the earthquake hit.

In all units of Fukushima Nuclear Power Plants this procedure was performed correctly. However, in such reactors, nuclear decay generates heat in the reactor core even after the nuclear fission process has stopped and the heat must be released from reactor to enable the reactor reach to cold shut-down point.

In Daiichi Fukushima plant only reactors 1 to 3 of the six reactors were operating when the earthquake hit the region. Following the earthquake, these three reactors were shut down automatically. However, when the tsunami hit the power plant it flooded generators, housed in low-lying rooms, and cut the electricity supply to cooling systems of units 1 to 3 . This caused the generated heat in the reactor core, despite being shut down, to increase and as the result the hot zirconium fuel rod cladding reacted with steam producing oxygen and hydrogen. The result was an explosion which destroyed the top of each unit and releasing steam/vapour polluted to radioactive isotopes into atmosphere [4].

The accident in Fukushima Nuclear Power Plants after the Chernobyl is the worst civilian nuclear incident in history. This accident once again brought into attention concerns over the associated risks with nuclear power plants which were forgotten after many years had passed from Chernobyl accident. The Fukushima accident and breakdown of cooling systems of 3 reactors demonstrated that unpredictable events can surprise us and cause tremendous damages. For instance, following the studies in the first few months of the accident in Fukushima it became clear that animals close to the explosion site had received radiation doses higher than the safe level, in particular three radioisotopes, ${ }^{134} \mathrm{Cs},{ }^{137} \mathrm{Cs}$ and ${ }^{131} \mathrm{I}$ [4].

\section{Important Nuclear Accidents}

The most important accidents that have occurred in short history of nuclear energy are listed below [5]-[7]:

1. Partial meltdown of Unit 2 in Three Mile Island Nuclear Power Plant on 28 March 1979 which is the most serious accident in the history of US nuclear energy. There was no casualty recorded in this accident. Prior to the Chernobyl disaster, the Three Mile Island accident was the most serious one in the history of the nuclear industry. 
2. Explosion in a Soviet Union nuclear submarine near the Vladivostok during refuelling in 10 August 1985. The explosion released a cloud of radioactivity toward Vladivostok but did not reach the city. Ten officers were killed in the explosion.

3. The 30 September 1999 Tokaimura accident was in a very small fuel preparation plant operated by Japan Nuclear Fuel Conversion Co. The accident was caused by bringing together too much uranium enriched to a relatively high level, causing a "criticality" (a limited uncontrolled nuclear chain reactions), which continued intermittently for 20 hours. A total of 119 people received a radiation dose over $1 \mathrm{mSv}$ from the accident, but only the three operators' doses were above permissible limits. Two of the doses proved fatal. The cause of the accident was "human error and serious breaches of safety principles", according to the IAEA.

4. The accident in the Chernobyl Nuclear Power Plant in 26 April 1986 is the worst nuclear accident in world history. In the morning of 26 April the reactor no. 4 in the Chernobyl Nuclear cites exploded and the subsequent explosions caused huge quantity of radioactive particles to be released into atmosphere for ten days [6] [7]. The amount of emitted radioactive particles out of reactor was four hundred times of the nuclear bomb dropped on Hiroshima. In this accident 30 of fire crews and the power plant personnel lost their lives due to Acute Radiation Syndrome [6] [7].

\section{Environmental Effects}

In Chernobyl accident people outside the power plant were exposed to internal and external radiation too. The internal radiation was due to breathing polluted air and consuming infected foods and water while the external radiation due to infected clouds and the leakage of radioactive particles on soil and other surfaces. Almost all the Xeon gases, $60 \%$ of Iodine, $40 \%$ of Caesium, $10 \%$ of Tellurium and $5 \%$ of remaining radioactive particles in the reactor core were released to the atmosphere which produced a radiation equal to $8 \times 10^{18} \mathrm{~Bq}$. A total area of $150,000 \mathrm{~km}^{2}$ were contaminated and became infertile by Caesium-137 with density of $37,000 \mathrm{~Bq} / \mathrm{m}^{2}$ [6].

The most affected areas with radioactive particles were around Chernobyl Nuclear Power Plant in North of Ukraine, South of Belorussia, Bryansk region of Western Russia [8]. However, the strong wind current carried the contaminated clouds to Finland, Sweden and the other countries in Northern Hemisphere [9]. On May the Second, this massive cloud-shape particle reached to UK and Japan and on May the Sixth, the effects of Chernobyl accident could be measured in Canada and USA [10].

From a radiological point of view, ${ }^{131} \mathrm{I}$, with half life of 8 days and ${ }^{137} \mathrm{Cs}$ with half life of 30 years are the most significant radioactive elements because the highest exposure to radiation in people are due to these two elements. ${ }^{131} \mathrm{I}$ has the main share in the internal radiating doses that Thyroid gland received after the accident but ${ }^{137} \mathrm{Cs}$ has the main share of doses received by tissues either through internal or external radiation. A small quantity of ${ }^{137} \mathrm{Cs}$ doses is existed for a few decades of being exposed to radiation [11].

One thousand emergency personnel which worked after the accident in the site have absorbed the most dose. 134 of them were affected by Acute Radiation Sickness. The radiation dose of external radioactive for these workers were around 100 milisieverts in the first year after the accident. During the first week, 16,000 people in areas with highest level of contamination in Ukraine and Belorussia were evacuated. The average effective dose among these people over this period was around 33 milisieverts. This was a very high dosage considering the maximum permitted annual doses for people are $2 \mathrm{mSv}$ [11]. In total 300,000 people were dislocated from their place of residence.

After this accident, ${ }^{137} \mathrm{Cs}$ was spread around $40 \%$ of Europe. To this date, in some parts of Europe the level of this element is still high to the extent that the consumption of meat of sheep grazing in certain parts of UK is not permitted [8] [9]. Furthermore, consuming mushrooms in some other parts are also not permitted.

For radioactive elements with short half life such as ${ }^{131} \mathrm{I}$, the major exposure is internal exposure that in the case of ${ }^{131}$ I can affect the thyroid gland. The thyroid gland uses iodine to produce thyroid hormones and cannot distinguish between radioactive iodine and nonradioactive iodine. If ${ }^{131}$ I were released into the atmosphere, people could absorb it in food products or water, or breathe it. In addition, if dairy animals razing in ${ }^{131}$ I contaminated grassland, the radioactive iodine will be incorporated into their milk. Consequently, people can receive internal exposure from drinking the milk or eating dairy products made from contaminated milk or leafy vegetables. Once inside the body, ${ }^{131}$ I will be absorbed by the thyroid gland exposing it to radiation and potentially increasing the risk for thyroid cancer or other thyroid problems.

In case of radioactive elements with long half life such as ${ }^{137} \mathrm{Cs}$ the human exposure will be done through the transferring contaminated soil to foods even weeks after the initial leak. After the Chernobyl accident no direct 
link was observed between the released ${ }^{137} \mathrm{Cs}$ to the environment and the health problems in humans.

The long term effects of the accident on human health was observed mostly in form of increase in Thyroid cancer rate particularly among children, over 6000 were diagnosed with Thyroid cancer which was the result of radioactive element ${ }^{131} \mathrm{I}$ (mostly due to consuming contaminated milk to ${ }^{131} \mathrm{I}$ ). However, only nine of the cancer stricken children lost their lives [12]. Due to unknown reasons, the effect of ${ }^{131}$ I on adults has been very low. If the children are given non radioactive Iodine Isotope on time this can prevent them of being stricken by Thyroid cancer because the Thyroid gland is saturated with stable Iodine (non-radioactive) and, therefore, there would be no need to absorb the ${ }^{131}$ I. However and sadly many of children in Chernobyl accident did not receive Iodine tablet but these tablets are still distributed in Japan.

Considering the previous nuclear accidents, it is expected that a number of gases such as Xenon, $\mathrm{Kr}$ and also radioactive elements such ${ }^{131} \mathrm{I},{ }^{134} \mathrm{Cs},{ }^{137} \mathrm{Cs}$ and possibly Strontium, Tellurium and Rubidium are released from Fukushima reactors. Xenon and Kr are not absorbed in body and, therefore, have low effects. The damage by ${ }^{131} \mathrm{I}$ and Cs are more acute, and absorption of ${ }^{131} \mathrm{I}$ by Thyroid gland can damage the DNA and cause the Thyroid cancer. Of course, encountering every radioactive particle is harmful [11].

\section{New Safer Technologies}

The design of Fukushima reactors is forty years old. Probably the newer generations of reactors with more comprehensive safety specifications/procedures and back up power generators could have withstood against the natural disasters. The designers of new generation nuclear power plants claim that their designs will not encounter such problems. Recently Igor Sechin (deputy prime minister of Russia) and Sergey Kiriyenko (the head of Rosatom, the Russian State nuclear energy corporation) have separately announced that tests conducted in new Russian nuclear power plants have proved that these power plants can withstand 14 meters high Tsunamis or earth quakes with magnitude 9 in Richter scale and crash of a jumbo jet 747 with full fuel tank on them [13].

Despite considering all safety standards and precautions one cannot guarantee $100 \%$ safety and free of any malfunctions in any of man-made machine or equipment. This applies to nuclear power plants too, no matter how modern is the design and up-to-date the technology of such power plants are ,one can encounter problems such as environmental pollution in form of radioactive leakage, military or terrorist attacks on the sites or other unforeseen events and accidents.

Another new generation of nuclear reactors is EPR. It is a third generation pressurized water reactor design. It has been designed and developed mainly by AREVA. This reactor design was called in Europe European Pressurized Reactor and the international name of it is Evolutionary Power Reactor [14]. Currently two prototypes are under construction in Finland and France. Westinghouse Electric is currently building its third generation reactor, called AP1000, in China [15]. But these new models of the nuclear fission reactors are not completely safe, they are not capable of resolving the safety issues associated with nuclear power plants completely, and the problem of hazardous radioactive wastes still remains.

With respect to the risks and dangers associated with fission-type nuclear reactors, and from the researches which have been done in the last five decades, it has been concluded that the Nuclear Fusion is the best method for production of electricity in future and Deuterium-Tritium compound is the best fuel for fusion reactors [1] [3] [16]-[19].

Fusion of nuclei of deuterium $\left(\mathrm{D} \equiv{ }^{2} \mathrm{H}\right)$ and tritium $\left(\mathrm{T} \equiv{ }^{3} \mathrm{H}\right)$ releases $17.6 \mathrm{MeV}$ (Figure 1) [1] [3].

$$
\mathrm{D}+\mathrm{T} \rightarrow{ }^{4} \mathrm{He}+n+17.6 \mathrm{MeV}
$$

Extraction of Deuterium from sea water using electrolysis is a simple and easy procedure and its cost compare with cost of other methods of producing electricity is negligible (a ratio of 1 out of 6700 units of Hydrogen available in water is Deuterium). The total available of Deuterium in oceans water is over $10^{15}$ metric tones which is far more than enough for producing electricity of the world for millions years [1].

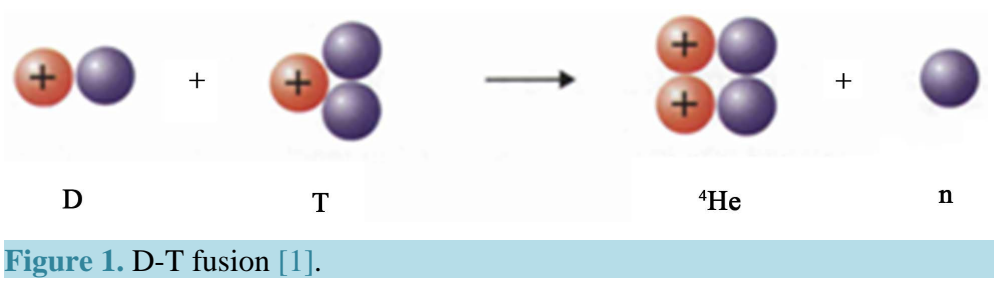


Small amounts of Tritium are generated as by product of fission-type reactors, in particular, in Canadian pressurized heavy water reactor (CANDU) which can be used for starting a fusion-type reactor. After that, the required Tritium for continuing the process must be produced in a breeding blanket around the reactor by reaction of produced neutrons during the process of fusion reaction with Lithium. Lithium can be found in huge quantities in earth crust and sea water [1] [3] [16]-[19].

Since the primary fuels for fusion-type reactors are Lithium and Deuterium, there is no problem which can be seen in the other-type reactors [1] [3] [16]-[19]. In other words:

1. The sources of fuel are almost unlimited.

2. The waste of fusion reaction of Deuterium-Tritium is mostly Helium which is a neutral gas. Therefore, there is no risk of having radioactive or chemical wastes.

3. The risks of explosion or any significant accident in fusion-type power plants are nearly zero.

For continuing the D-T reaction at a sufficient rate, the temperature of the fuel must be increased to very high values (in the case of D-T reaction more than $10^{8}$ Kelvin) and confined for enough time. In these temperatures Matter is in the form of plasma. Alpha particles produced by the D-T reaction provide a source of heat to maintain $10^{8}$ degree Kelvin in the plasma.

Nowadays, two major methods are considered for constructing fusion-type power plants, magnetic confinement fusion (MCF) and inertial confinement fusion (ICF), several devices have been constructed on the base of these methods [1] [3] [16]-[19].

The best candidate for nuclear fusion reactors is Tokomak (Figure 2) that is a MCF machine. Tokamak is a toroidal chamber that in it the plasma is confined by a strong toroidal magnetic field and a much weaker poloidal field, the toroidal field is produced by external electric current flowing in the coils wound around the torus and the poloidal field is generated by the electric current flowing in the plasma around the torus [16]-[20]. Three important methods of heating the Tokamak plasmas are ohmic heating, neutral beam heating and radio-frequency heating [1] [16]-[20]. Since the second half of 1980s an international cooperation started among Japan, European Union, United States and Soviet Union on a nuclear fusion research and engineering project named International Thermonuclear Experimental Reactor (ITER) [1] [3]. Since the beginning of $21^{\text {th }}$ century, China, India and South Korea have joined the project. The ITER fusion reactor itself has been designed to produce 500 megawatts of output power for 50 megawatts of input power. The cost of building this reactor is estimated around 16 billion Euro's [1] [3]. It is estimated that building fusion-type reactor for commercial purpose would be possible by end of 2030s or beginning 2040s [1] [3].

\section{Conclusions}

It seems that important problems with nuclear fission reactors can be reduced; the new designed nuclear power plants can withstand natural disasters, mainly earth quake and tsunami. However, in these new generations of fission-type nuclear power plants, the challenge of preparing the required fuel, dangerous radioactive waste and risks of incidents such as explosion and leak still exist.

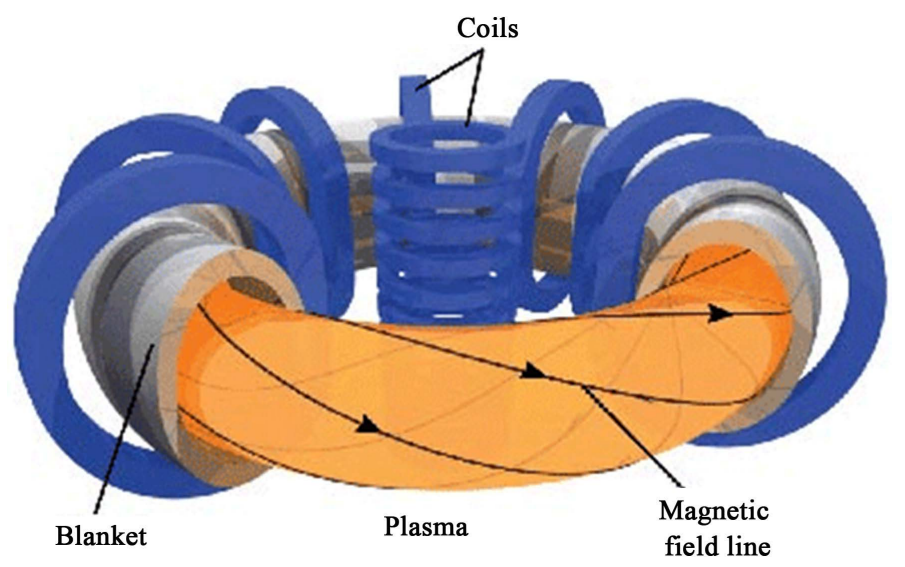

Figure 2. Tokamak [20]. 
Nuclear fusion is the best candidate for providing energy in the future; it does not have any of the problems of the other energy generation methods. A large number of investments have put on developing fusion-type reactors in the last 6 decades, but a lot of theoretical and technical problems must be solved and still many years are left for the commercial usage of such type of reactors.

\section{References}

[1] McCracken, G. and Stott, P. (2005) Fusion: The Energy of Universe. Elsevier Academic Press, Massachusetts.

[2] World Energy Council (2006) Energy Policy Scenarios to 2050. World Energy Council, London.

[3] Jriedberg, J. (2007) Plasma Physics and Fusion Energy. Cambridge University Press, Cambridge.

[4] Ten Hoeve, J.E. and Jakobson, M.Z. (2012) World Wide Health Effects of the Fukushima Daiichi Nuclear Accident. Energy \& Environmental Science, 5, 8743-8757. http://dx.doi.org/10.1039/c2ee22019a

[5] Ryan, M.E. (2001) The Tokaimura Nuclear Accident: A Tragedy of Human Errors. Journal of College Science Teaching, 31, 42-48.

[6] Mould, R.F. (2006) Chernobyl Records: The Definitive History of the Chernobyl Catastrophe. Taylor \& Francis, London.

[7] Gudikson, P.H., Harvey, T.F. and Lange, R. (1989) Chernobyl Source Term, Atmospheric Dispersion and Dose Estimation. Health Physics, 57, 697-706. http://dx.doi.org/10.1097/00004032-198911000-00001

[8] Stone, R. (2001) Living in the Shadow of Chernobyl. Science, 292, 420-426. http://dx.doi.org/10.1126/science.292.5516.420

[9] Simon, A.P. and Wilson, H. (1986) Tracking the Cloud from Chernobyl. Journal of New Science, 1517, 42-45.

[10] Ayoma, M., Hirosa, K., Susuki, Y., Inoke, H. and Sugimera, Y. (1988) High Level Radioactive Nuclides in Japan. Nature, 321, 819-820. http://dx.doi.org/10.1038/321819a0

[11] Cember, H. (1983) Introduction to Health Physics. Pergamon Press, Oxford.

[12] International Atomic Energy Agency (2003) The Chernobyl Forum. IAEA, Vienna.

[13] Socor, V. (2014) Rosatom Lands Nuclear Energy Project in Hungary by Western Default. Eurasia Daily Monitor, 11, 25.

[14] Simons, A. and Bauer, C. (2012) Life Cycle Assessment of the European Pressurized Reactor and the Influence of Different Fuelcycle Strategies. Proceedings of the Institution of Mechanical Engineers, Part A: Journal of Power and Energy, 226, 427-444.

[15] Rahim, F.C., Rahgoshay, M. and Mousavian, S.K. (2012) A Study of Large Break LOCA in the AP1000 Reactor Containment. Progress in Nuclear Energy, 54, 132-137. http://dx.doi.org/10.1016/j.pnucene.2011.07.004

[16] Wesson, J. (2006) The Science of Jet. 2nd Edition, JET Joint Undertaking, Abingdon.

[17] Niu, K. (1989) Nuclear Fusion. Cambridge University Press, Cambridge.

[18] Miyamoto, K. (2004) Plasma Physics and Controlled Nuclear Fusion. University of Tokyo Press, Tokyo.

[19] Wesson, J. (2003) Tokamaks. 3rd Edition, Clarendon Press, Oxford.

[20] Ariola, M. and Oironty, A. (2008) Magnetic Control of Tokamak Plasmas. Springer, Berlin. 